\title{
Establishment and Application of a High Throughput Model for Rho Kinase Inhibitors Screening Based on Fluorescence Polarization
}

\author{
WeiGang Duan, LiXin Sun, Jun Liu, XuDong Wu, LuYong Zhang, ${ }^{*}$ and Ming Yan \\ Jiangsu Center for Drug Screening, China Pharmaceutical University; 1, Shennong Road, Nanjing 210038, P. R. China. \\ Received December 1, 2005; accepted February 23, 2006
}

\begin{abstract}
Rho kinase (ROCK) inhibitors are effective candidates for neural or cardiovascular disorders. High throughput model for screening ROCK inhibitors is a basic foundation to pick up ROCK inhibitors from thousands of compounds for drug developing. The high throughput model was established based on purified recombinant rat ROCK catalytic domain (rROCK-CD) from Escherichia coli $(E$. coli). There are two steps of reaction in the model: incubation of $5.0 \mu \mathrm{l}$ recombinant rROCK-CD $(2.0 \mu \mathrm{g} / \mathrm{ml}), 5.0 \mu \mathrm{l}$ different compounds, $5.0 \mu \mathrm{l}$ fluorescent S6-peptide (200 nM), and $5.0 \mu \mathrm{IATP}\left(10 \mu_{\mathrm{M}}\right)$ at $37^{\circ} \mathrm{C}$ for $60 \mathrm{~min}$ was made the first reaction, and the second reaction was made by incubating them with additional $60 \mu \mathrm{l}$ binding reagent at ambient temperature for $30 \mathrm{~min}$. The phosphorylated S6 peptide can bind to a binding reagent, and the fluorescence varies from low polarization to high according to the amount of the phosphorylated peptide. $\mathrm{IC}_{50}$ was calculated based on polarization variation. Compound, which $\mathrm{IC}_{50}$ was less than $10 \mu \mathrm{M}$, was recognized as a lead compound which taken bioactivity evaluation in PC12 by observing neurite outgrowth. The $Z^{\prime}$-factor of the model is 0.81 (above 0.5 ). The model screened five lead compounds from 3294, which promoted neurite outgrowth to different extent. The results suggested that the model is suitable for high throughput screening (HTS), and the five lead compounds are worth of further investigation.
\end{abstract}

Key words Rho kinase inhibitor; high throughput screening; fluorescence polarization

Rho kinase, known as Rho-associated coiled-coil forming protein serine/threonine kinase (ROCK) is one of the central regulatory molecules for cytoskeleton control and cell adhesion process. ${ }^{1)}$ ROCK also involves in other cell functions such as apoptosis ${ }^{2}$ and tumor invasiveness. ${ }^{3)}$ ROCK is thought to play an important role in a variety of cellar functions such as stress fiber formation, focal adhesion formation, cell aggregation, cell morphology, cytokinesis, cell migration, and $\mathrm{Ca}^{2+}$-sensitization in the smooth muscle. ${ }^{1,4)}$ ROCK is also involved in regulation of the amyloid precursor protein processing in Alzheimer Disease, ${ }^{5)}$ and regards as a promising target for nerve disorders. ${ }^{6}$ ROCK inhibitors are beneficial candidates for a wide range of diseases such as hypertension, inflammation, cancer, ${ }^{3)}$ erectile dysfunction, ${ }^{7)}$ and injury caused by ischemia and reperfusion. ${ }^{8)}$

There are two types of ROCK: ROCK-I (ROCK- $\beta$ ) mainly found in non-neural cells, and ROCK-II (ROCK- $\alpha$ ) in central nerve system (CNS). ${ }^{6}$ ROCK catalytic domain (ROCK$\mathrm{CD}$ ) is activated by binding with the activated form of a low molecular weight G protein, Rho. ${ }^{9}$ High throughput screening (HTS) model based on ROCK-CD is an important foundation to pick up ROCK inhibitors for drug developing from thousands of compounds. Early ROCK inhibitors were discovered, or identified mainly by scintillation proximity assay (SPA) in vitro. ${ }^{10)}$ The accuracy and sensitive of SPA system in detecting kinase activity was embedded in scientists' brain; however, radiation of isotope is a potential harm factor to operators, and the assay system should be practiced in special laboratories; which limited its wide application. Here, a new HTS model based on fluorescence polarization was established, which could overcome the disadvantages.

\section{MATERIALS AND METHODS}

Harvest Recombinant ROCK-CD Recombination and purification of rat ROCK-CD (rROCK-CD) were followed the procedure of ref. 11. Briefly, the cDNA fragment of $1644 \mathrm{nt}(13-1656)$ encoding the amino acids 5-552 of rat ROCK-II was cloned with polymerase chain reaction (PCR). Primer A was 5'-ATGAGCGGATCCCCGCCGACGGGGAAAAT-3', and primer B was 5'-ACCTCTCTCGAGTATCTGAGAGCTCTGGT-3'. Sequenced cDNA was ligated to $\mathrm{pET} 28 \mathrm{a}(+)$ (Novagen, U.S.A.), and transferred to Escherichia coli (E. coli) $\mathrm{BL}(21)$ with the help of $\mathrm{CaCl}_{2}$ treatment. Positive clones that expressed rROCK-CD were screened out by routine $10 \%$ SDS-PAGE. The recombinant protein was a $67.4 \mathrm{kD}$ fusion protein with a (His) ${ }_{6}$ tag at its N-terminus. rROCK-CD, as inclusion bodies, was extracted, purified, and refolded by $\mathrm{Ni}^{2+}$ chelating column (Amersham Biosciences, Sweden).

rROCK-CD Activity Assay The activity of the protein was evaluated based on its ability to phosphorylate its specific substrate, S6-peptide (AKRRRLSSLRA) tagged with fluorescein isothiocyanate on the free amino-group at its $\mathrm{N}$ terminus (Molecular Devices Company, U.S.A.). The reaction of activity assay was composed of two steps: 1) incubation of $5.0 \mu \mathrm{l} \mathrm{S6-peptide}(200 \mathrm{nM}), 5.0 \mu \mathrm{l}$ ATP $(10 \mu \mathrm{M}), 5.0 \mu \mathrm{l}$ reaction buffer $\left(10 \mathrm{~mm}\right.$ Tris- $\mathrm{HCl}, 10 \mathrm{~mm} \mathrm{MgCl}_{2}, 0.1 \% \mathrm{BSA}$, $0.05 \% \mathrm{NaN}_{3}, \mathrm{pH} 7.2$ ) at $37 \pm 0.5^{\circ} \mathrm{C}$ for $60 \mathrm{~min}$ made the phosphorylation reaction; then 2) $60 \mu$ l binding solution was added into the reaction system to terminate phosphorylation, and incubated for another $30 \mathrm{~min}$ at ambient temperature to ensure binding reaction. The fluorescence was able to vary from low fluorescence polarization (FP) to high according to the amount of phosphorylated S6-peptide by binding to the binding reagent (Molecular Devices Company, U.S.A.). The fluorescence was excited at $485 \mathrm{~nm}$ and emitted at $515 \mathrm{~nm}$. FP was detected by Tecan Reader (Megallan, Swiss). High FP indicates high activity of rROCK-CD. The activity of rROCK-CD was compared with that of standard human ROCK-CD (hROCK-CD, $63.3 \mathrm{kD}$; Upstate Company, U.S.A.). $\mathrm{IC}_{50}$ of Y-27632 (Alexis Biochemicals, U.S.A.), a 
ROCK selective inhibitor, for both ROCK-CDs, was calculated based on the FP assay system.

Model Evaluation The model was evaluated with $Z^{\prime}$ factor according to formula (1.1). ${ }^{12)}$

$$
Z^{\prime}=1-\frac{3 \sigma_{\mathrm{c}+}+3 \sigma_{\mathrm{c}-}}{\left|\mu_{\mathrm{c}+}-\mu_{\mathrm{c}-}\right|}
$$

Drug Screening Once the activity of the recombinant rROCK-CD was conformed, drug screening was carried out. $5.0 \mu \mathrm{l}$ compounds, rROCK $(2 \mu \mathrm{g} / \mathrm{ml})$, S6-peptide, and ATP, were automatically sampled to 384-well plates by Hydra II robot (Matrix, U.S.A.). Conditions of reaction and parameters of FP detection were as same as those in rROCK-CD activity assay.

There are three steps in the whole procedure of screening: 1) different compounds $(0.1 \mathrm{~mm})$ were screened once by the model, and compounds that inhibited the activity of rROCKCD more than $70 \%$ were screened out; 2 ) then screened them once more in the same condition to limit error possibly occurred, and compounds, which were able to inhibit rROCKCD more than $80 \%$, were regarded as hits; 3 ) the hits were adjusted to different concentration in order to detect their $\mathrm{IC}_{50}$ based on the model which measured their inhibition potency. If the $\mathrm{IC}_{50}$ was less than $10 \mu \mathrm{M}$, the hit was recognized as a lead compound, which deserves bioactivity evaluation in PC12 compared with Y-27632.

Bioactivity Evaluation in PC12 PC12 was obtained from American Type Culture Collection (ATCC) via Peking Union Medical College. One hundred and eighty microliters PC12 $\left(8 \times 10^{4} / \mathrm{ml}\right)$ was seeded in every well of 96 -well plates, and incubated in Ham's F12K medium (Hyclone, U.S.A.) with $2 \mathrm{~mm}$ L-glutamine adjusted to contain $1.5 \mathrm{~g} / 1$ sodium bicarbonate, with 15\% horse serum (Invitrogen, U.S.A.) and $2.5 \%$ fetal bovine serum (Hyclone, U.S.A.), in atmosphere containing $5 \% \mathrm{CO}_{2}$, at $37.0^{\circ} \mathrm{C}$. PC12 exposed to $20 \mu \mathrm{M}$ of different lead compounds for $24 \mathrm{~h}$. The activity of the compounds was evaluated based on their ability to promote neurite outgrowth.

The morphology of the cells was categorized into three groups: neurite-positive cells, round cells, and the other cells. The cells with longer neurites than their soma were defined as neurite positive cells. The other cells had various features including micro-spikes, ruffles and a flattened appearance. ${ }^{13)}$ The ratio of positive cell was calculated based on formula (1.2) to evaluate the activity.

$$
\text { ratio }(\%)=\frac{\text { positive cells }}{\text { total cells }} \times 100 \%
$$

\section{RSULTS}

RT-PCR and Purification of rROCK-CD The RT-PCR product was detected by $0.8 \%$ agarose electrophoresis (Fig. 1A), which indicated the product could be the sequence of $1644 \mathrm{bp}$, the cDNA fragment was verified by sequencing. The purified recombinant protein is $67.4 \mathrm{kD}$ (Fig. 1B), which amino acid sequence was as same as that of ref. 11; its purity was no less than $95 \%$ by electrophoresis detection.

HTS Model and rROCK-CD Activity Assay Result in
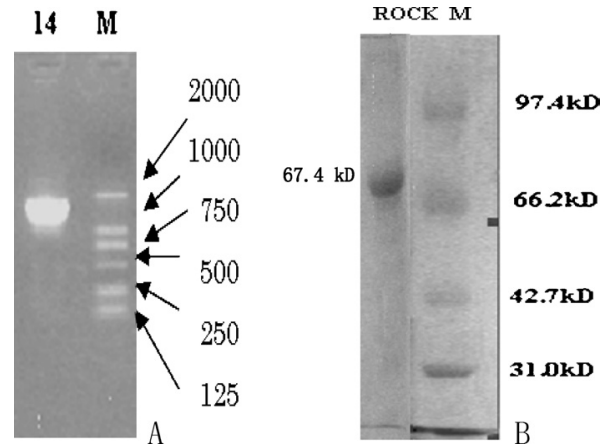

Fig. 1. Result of RT-PCR and Protein

RT-PCR fragment was detected by $0.8 \%$ agarose electrophoresis, and the fragment was of $1644 \mathrm{bp}$ (A). rROCK-CD was detected by $10 \%$ SDS-PAGE after purified by HiTrap chelating column, desalinated by ultrafiltration, which purity was of no less than $95 \%$ by electrophoresis detection (B).

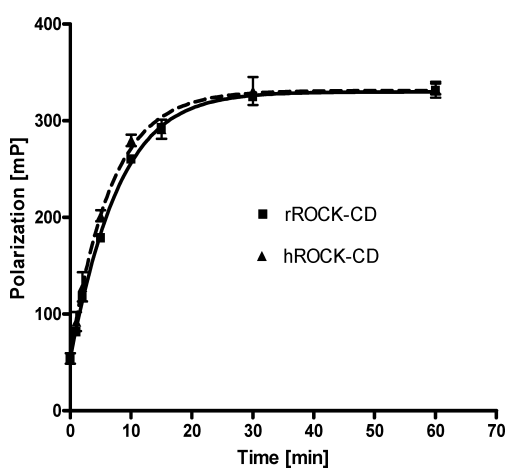

Fig. 2. Result of Recombinant ROCK Activity

rROCK-CD was assayed with ROCK activity FP assay system compared with hROCK-CD (standard ROCK-CD) (mean \pm S.D., $n=3$ ). Condition: $37^{\circ} \mathrm{C}, 2 \mu \mathrm{g} / \mathrm{ml}$ enzyme, 200 nм S6-peptide, $10 \mu \mathrm{M}$ ATP.

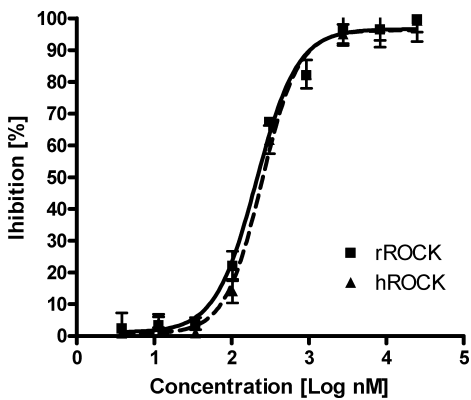

Fig. 3. rROCK-CD Inhibited by Y-27632

Y-27632 inhibited rROCK-CD and hROCK-CD in a dose-dependent manner. Both of the inhibition curves were similar. The $\mathrm{IC}_{50}$ were calculated by Bliss method, ${ }^{14}$ $0.26 \pm 0.03 \mu \mathrm{m}$ for rROCK-CD and $0.34 \pm 0.02 \mu \mathrm{M}$ for hROCK-CD in the assay system. Conditions: $37^{\circ} \mathrm{C}, 25 \mu \mathrm{g} / \mathrm{ml}$ enzyme, $200 \mathrm{~nm}$ S6-derived peptide, $10 \mu \mathrm{M}$ ATP, $60 \mathrm{~min}$ reaction (mean \pm S.D., $n=3$ ).

Fig. 2 showed that the property of rROCK-CD activity was similar to that of hROCK-CD. There is linear relationship between reaction time (within $15 \mathrm{~min}$ ) and reaction speed for both ROCK-CDs.

Y-27632, inhibited activity of both rROCK and hROCK in a dose-dependent manner in the assay system, the inhibition pattern of them and $\mathrm{IC}_{50}(0.26 \pm 0.02 \mu \mathrm{M}$ for $\mathrm{rROCK}-\mathrm{CD}$, and $0.35 \pm 0.02 \mu \mathrm{M}$ for hROCK-CD) were also similar (Fig. 3).

Model Evaluation $Z^{\prime}$-factor was calculated by formula (1.1). The $Z^{\prime}$-factor of the model is 0.81 in the screening system. 
Table 1. Five Lead Compounds Were Screened out from 3294

\begin{tabular}{lllcc}
\hline \hline Compounds & \multicolumn{1}{c}{ Mol Fm. } & M.W. & $\mathrm{IC}_{50}$ & Remarks \\
\hline ZM100002 & $\mathrm{C}_{28} \mathrm{H}_{35} \mathrm{~N}_{3} \mathrm{O}_{10} \mathrm{~S}$ & 615.68 & 1.26 & \\
$\mathrm{ZM} 100012$ & $\mathrm{C}_{32} \mathrm{H}_{35} \mathrm{~N}_{3} \mathrm{O}_{9}$ & 614.64 & 9.48 & \\
$\mathrm{ZM} 100079$ & $\mathrm{C}_{20} \mathrm{H}_{28} \mathrm{~N}_{6} \mathrm{O}_{5}$ & 437.48 & 1.81 & \\
ZM100085 & $\mathrm{C}_{12} \mathrm{H}_{24} \mathrm{~N}_{4} \mathrm{O}_{2}$ & 258.35 & 1.35 & \\
ZM103315 & non & 456.00 & 3.24 & a) \\
Y-27632 & $\mathrm{C}_{14} \mathrm{H}_{21} \mathrm{~N}_{3} \mathrm{O}$ & 247.30 & 0.26 & Ctrl \\
\hline
\end{tabular}

Five lead compounds were screened out based on their $\mathrm{IC}_{50}$ less than $10 \mu \mathrm{M}$. Their inhibition was weaker than that of Y-27632 in this assay. Mol Fm: molecular formula; MW: molecular weight; $a$ ) nature product.

Drug Screening In the first screening, 144 compounds were screened out from 3294 collected from different institutions. In the second, 17 hits were discovered. Finally, five lead compounds (Table 1) were identified from the hits, for their $\mathrm{IC}_{50}$ was below the standard of $10 \mu \mathrm{M}$. Their inhibition on rROCK-CD is weaker than Y-27632, the bioactivity was investigated in PC12 cell (below).

Bioactivity Evaluation of the Lead Compounds in PC12 PC12, a polygonal pheochromocytoma cell (Fig. $4 \mathrm{~A})$, is inducible to grow neurite by nerve growth factor (NGF), ${ }^{15)}$ or ROCK inhibitor, Y-27632 (Fig. 4B). All of the lead compounds were able to do so to different extents as showed in Figs. 4C-G.

According to the length of neurite, the bioactivity of $20 \mu \mathrm{M}$ ZM100002 (Fig. 4C), or ZM100079 (Fig. 4E) is near to that of $10 \mu \mathrm{M}$ Y-27632 (Fig. 4B); however, the other three, ZM100012 (Fig. 4D), ZM100085 (Fig. 4F), and ZM103315 (Fig. 4G), is less potent.

In order to quantitatively measure their bioactivity, ratio of positive PC12 was calculated. According to their ratio (Fig. 5), Y-27632 has stronger effect on neurite outgrowth, while the effect of ZM100012 is weaker than any other compounds. Although the longest length of neurite induced by $20 \mu \mathrm{M}$ ZM100002 or $20 \mu \mathrm{M}$ ZM100079 was near to that by $10 \mu \mathrm{M}$ Y-27632 (Fig. 4), there was significant difference between them according to their ratio of positive $\mathrm{PC} 12$ $(p<0.05)$. Figure 5 indicated that there would be a rough relationship between activity of neurite outgrowth and ROCK inhibition.

\section{DISCUSSION}

ROCK is a central enzyme associated in many cell functions, and its catalytic domain was recognized to be the first 543 amino acid residua. ${ }^{16)}$ Other domains (including Rho Binding Domain) in ROCK regulate the catalytic activity. Classical ROCK inhibitors, like Y-27632 and fasudil, ${ }^{17)}$ can selectively bind to the catalytic domain and inhibit its activity. Therefore, purified ROCK-CD, as an executive domain, is very useful in screening ROCK inhibitors.

Classical ROCK used for drug screening was mainly obtained from $S f-21$ cell through recombination, ${ }^{16)}$ or extracted from animal tissues directly; which are relatively of high cost. In order to save the cost of drug screening, active recombinant rROCK-CD was harvested from E. coli, and was employed to establish the high throughput model. Duan et al. made the try to harvest active recombinant rROCK-CD from E. coli recently, ${ }^{11)}$ which was a foundation to the HTS model at lower cost. Activity curves in Fig. 2 and in Fig. 3 showed
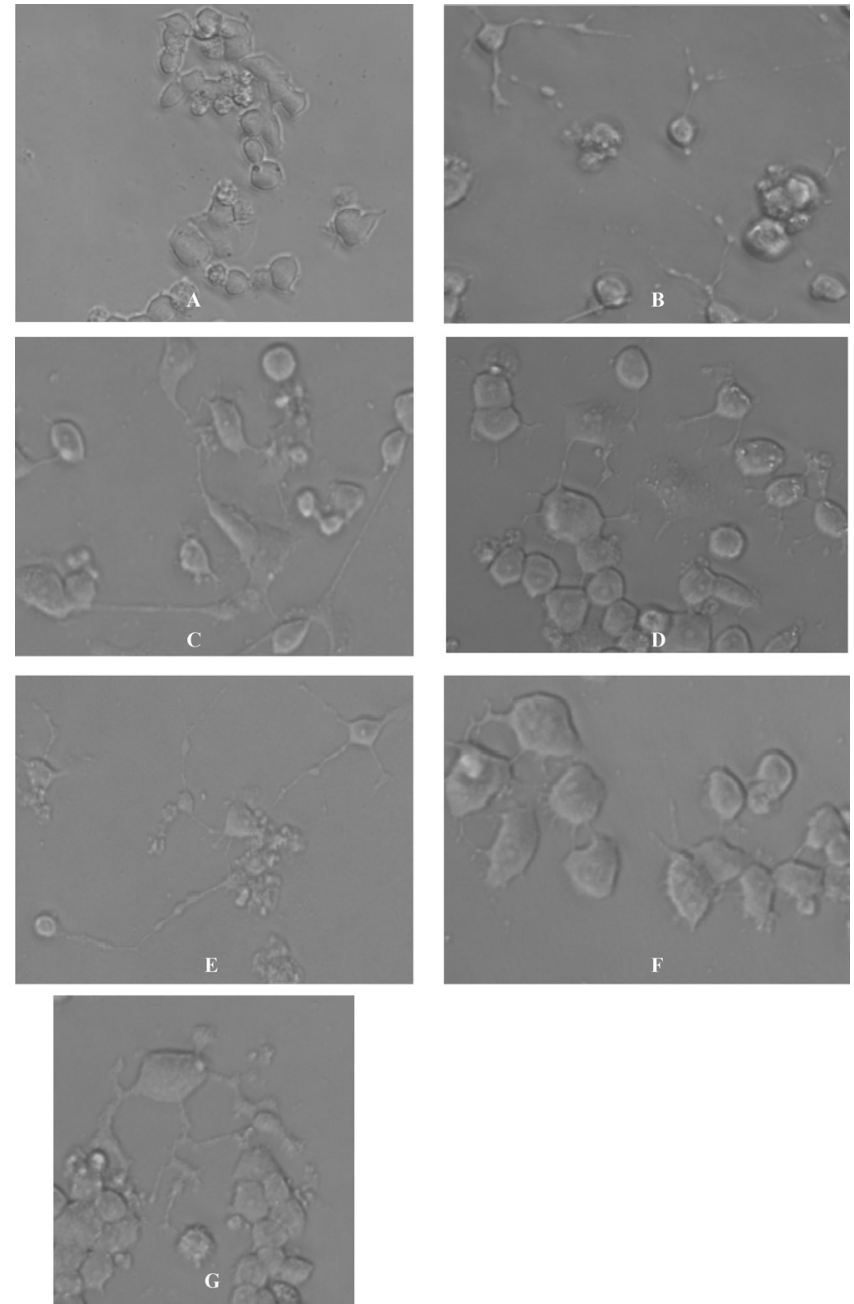

Fig. 4. Activity Evaluation of the Five Lead Compounds in PC12 (×330)

PC12 was exposed to PBS, Y-27632, or lead compounds for $24 \mathrm{~h}$. PBS was not able to promote neurite outgrowth in PC12 (A), but all the five lead compounds and Y27632 were able to. According to the length of the neurite, the activity of $20 \mu \mathrm{M}$ ZM100002 (C) or ZM100079 (E) is near to that of Y-27632 (B), and is more potent than that of the other three, ZM100012 (D), ZM100085 (F), and ZM103315 (G). A: negative control, treated with $20 \mu 1$ PBS; B: exposed to $10 \mu \mathrm{M} \mathrm{Y-27632;} \mathrm{C,} \mathrm{D,} \mathrm{E,} \mathrm{F,} \mathrm{or}$ G: exposed to $20 \mu \mathrm{M}$ ZM100002, ZM100012, ZM100079, ZM100085, and ZM103315 respectively.

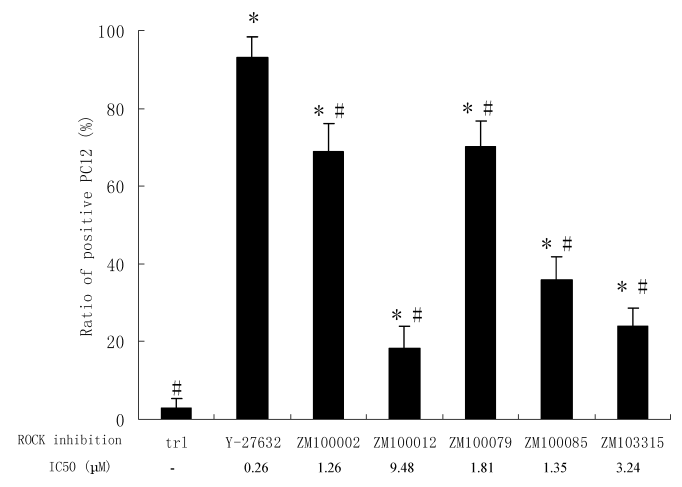

Fig. 5. Ratio of Positive PC12 Induced by Different Compounds (Mean \pm S.D., $n=3$ )

PC12 was exposed $10 \mu \mathrm{M} \mathrm{Y-27632,} \mathrm{or} 20 \mu \mathrm{M}$ lead compounds for $24 \mathrm{~h}$. All of them were able to induce neurite outgrowth to different extent $(p<0.05)$. The bioactivity was measured by ratio of positive PC12. Y-27632, with a lowest $\mathrm{IC}_{50}$, was more potent than other compounds in this effect. $* p<0.05$ versus ctrl $(20 \mu \mathrm{l} \mathrm{PBS})$; $\# p<0.05$ versus $\mathrm{Y}$ 27632. One-way ANOVA was applied. 
similar activity property and inhibition property of both rROCK-CD and hROCK-CD, respectively. Compared with standard human ROCK-CD, and based on the activity FP assay system, Duan's report ${ }^{11)}$ indicated that the parameters (including $K_{\mathrm{m}}, K_{\text {cat }}$, and $\mathrm{IC}_{50}$ of Y-27632) of rROCK-CD harvested from $E$. coli under the same procedure, were also similar to those of hROCK-CD. All the early results indicated that the purified rROCK-CD from E. coli is feasible for drug screening.

The classical selective substrates for ROCK are myosin light chain (MLC), and myosin light chain phosphatase (MLCP) ${ }^{6}$ which regulate actin contraction. Trauger's report $^{18)}$ suggested that S6-peptide is also one of selective substrates for ROCK, and conformed by Turner et al. ${ }^{16)}$ The $\mathrm{IC}_{50}$ of Y-27632 based on fluorescent S6-peptide in present study was similar to Turner's report, ${ }^{16}$ ) which suggested the FP assay system is effective to determine ROCK activity. Takami et al. ${ }^{10)}$ had successfully screened 69000 compounds based on SPA model, the substrate in their experiment also was S6-peptide.

With the help of a robot in sampling, it is possible to screen more than 80000 compounds in one work-day with the HTS model. $Z$ '-factor above 0.5 was thought to be a hallmark to evaluate the stability of a HTS model. ${ }^{12)}$ The $Z^{\prime}$-factor of this model was 0.81 , which suggested this model is acceptable for HTS. ${ }^{12)}$ Usually, dimethyl sulfoxide (DMSO) was employed as universal solvent for new compounds in drug assay. If the concentration of DMSO was controlled below $13 \%$, the interference in the assay system was omissible (data not shown). So, no consideration of solvent interference should be taken into in routine screening if DMSO was applied. In this study, compounds were dissolved in DMSO to make their stock solution; DMSO was controlled below $1 \%$ in the assay system.

PC12 is a normal tool cell for neural science research. PC12 is inducible to grow neurite by NGF. ${ }^{15)}$ Neurtie outgrowth was recognized as an initial step for neuron regeneration after injury. ${ }^{19)}$ ROCK inhibitors, like Y-27632, were identified as beneficial agents for neurite outgrowth in PC12 cell $^{20)}$ and in spinal cord regeneration. ${ }^{21)}$ Present study supported the result of neurite outgrowth, even further, Y-27632 was able to promote neurite outgrowth in PC12 at absent of any serum (data not shown); which suggested the activity is independent of NGF or other cytokins. Since ROCK activation was able to call off neurtie outgrowth induced by $\mathrm{NGF}^{6,22)}$ the results also suggested ROCK may be at the downstream of neurtie outgrowth pathway induced by NGF.

The neurite outgrowth may be associated with many molecular targets. Inhibition on RhoA, or ROCK, activation of Cdc42, Rac1, TrkA or other molecules ${ }^{23,24)}$ will promote or help to promote neurite outgrowth. ROCK is an inhibitory target at relative downstream of neurite outgrowth pathways; ROCK is activated by binding to active form of RhoA, while NGF inhibits ROCK activation by suppressing RhoA activation. $^{22)}$ In another word, activation of ROCK can antagonize neurite outgrowth caused by $\mathrm{NGF}^{6,22}$ while inhibition on ROCK will promote this effect ${ }^{20,25)}$ all of which suggested that the relationship between ROCK inhibition and neurite outgrowth could be established at large. Since the HTS model in vitro is the first step in drug discovery, bioactivity assay in cell or animal is a good supplement. Present study took the advantage of ROCK inhibitors promoting neurite outgrowth in PC12 cell model to evaluate the bioactivity of lead compounds screened out through the HTS model.

According to Takami's report, ${ }^{10)}$ compounds, whose $\mathrm{IC}_{50}$ is less than $3 \mu \mathrm{M}$, could be grouped to strong ROCK inhibitors. Present study set the standard to $10 \mu \mathrm{M}$ in order to limit false negative. Though the $\mathrm{IC}_{50}$ of the five lead compounds was bigger than that of Y-27632, they also shared the ability of neurite outgrowth, and their bioactivity of this kind was roughly of relationship with its ROCK inhibition. Thus, the bioactivity evaluation in PC12 supported the results of the HTS model.

Although SPA model is effective in screening ROCK inhibitor, the radiation hampers its wide application in normal laboratories. Usually, assay in SPA model needs some separation performance, which limits its throughput. The HTS model base on FP overcomes the disadvantages obviously.

Taken collectively, a high throughput model was established for screening ROCK inhibitors based on FP. And the five lead compounds, especially ZM100002 and ZM100079, screened out through the model, are worth of further investigation.

Acknowledgements The study is supported by Megaproject of Science Research for the 10th Five-year Plan (No. 2004AA2Z3785) of Ministry of Science and Technology of P. R. China.

\section{REFERENCES}

1) Fukata Y., Amano M., Kaibuchi K., Trends Pharmacol. Sci., 22, 32 39 (2001).

2) Sebbagh M., Hamelin J., Bertoglio J., Solary E., Breard J., J. Exp. Med., 201, 465-471 (2005).

3) Sun B., Nishihira J., Yoshiki T., Kondo M., Sato Y., Sasaki F., Todo S., Clin. Cancer Res., 11, 1050-1058 (2005).

4) Mammoto A., Huang S., Moore K., Oh P., Ingber D. E., J. Biol. Chem., 279, 26323-26330 (2004).

5) Zhou Y., Su Y., Li B., Liu F., Ryder J. W., Wu X., Gonzalez-DeWhitt P. A., Gelfanova V., Hale J. E., May P. C., Paul S. M., Ni B., Science, 302, 1215-1217 (2003).

6) Bernhard K. M., Helmut M., Nicole T., Nat. Rev. Drug Discov., 4, $388-398$ (2005)

7) Mills T. M., Lewis R. W., Wingard C. J., Linder A. E., Jin L., Webb R. C., Int. J. Impot. Res., 15 (Suppl. 5), S20-S24 (2003).

8) Bao W., Hu E., Tao L., Boyce R., Mirabile R., Thudium D. T., Ma X L., Willette R. N., Yue T. L., Cardiovasc. Res., 61, 548-558 (2004).

9) Kawano Y., Fukata Y., Oshiro N., Amano M., Nakamura T., Ito M., Matsumura F., Inagaki M., Kaibuchi K., J. Cell Biol., 147, 10231038 (1999).

10) Takami A., Iwakubo M., Okada Y., Kawata T., Odai H., Takahashi N., Shindo K., Kimura K., Tagami Y., Miyake M., Fukushima K., Inagaki M., Amano M., Kaibuchi K., Iijima H., Bioorgan. Med. Chem., 12, 2115-2137 (2004).

11) Duan W., Wang S., Chen M., Wang C., Zhang L., Liu J., Sun L., Yan M., Biol. Pharm. Bull., 29, 38-42 (2006).

12) Zhan J. H., Chung T. D. Y., Oldenbur K. R., J. Biomol. Screen, 4, 6773 (1999)

13) Tanaka H., Yamashita T., Yachi K., Fujiwara T., Yoshikawa H., Tohyama M., Neuroscience, 127, 155-164 (2004).

14) Chen S. G., Zhou R. Q., "Enzymology," Fudan University Press, Shanghai, P.R. China, 2001.

15) Greene L. A., Tischler A. S., Proc. Natl. Acad. Sci. U.S.A., 73, 2424 2428 (1976).

16) Turner M. S., Lin F. F., Trauger J. W., Stephens J., LoGrasso P., Arch. Biochem. Biophys., 405, 13-20 (2002).

17) Suzuki Y., Yamamoto M., Wada H., Ito M., Nakano T., Sasaki Y., 
Narumiya S., Shiku H., Nishikawa M., Blood, 93, 3408-3417 (1999).

18) Trauger J. W., Lin F. F., Turner M. S., Stephens J., LoGrasso P. V., Biochemistry, 41, 8948-8953 (2002)

19) Fournier A. E., Takizawa B. T., Strittmatter S. M., J. Neurosci., 23 1416-1423 (2003).

20) Fujita A., Hattori Y., Takeuchi T., Kamata Y., Hata F., Neuroreport, 12 3599-3602 (2001).

21) Dergham P., Ellezam B., Essagian C., Avedissian H., Lubell W. D., McKerracher L. J., Neurosci., 22, 6570-6577 (2002).
22) Yamaguchi Y., Katoh H., Yasui H., Mori K., Negishi M., J. Biol. Chem., 276, 18977-18983 (2001).

23) Nikolic M., Int. J. Biochem. Cell Biol., 34, 731-745 (2002).

24) Chakrabarti K., Lin R., Schiller N. I., Wang Y., Koubi D., Fan Y. X., Rudkin B. B., Johnson G. R., Schiller M. R., Mol. Cell. Biol., 25, 5106-5118 (2005).

25) Yamazaki M., Miyazaki H., Watanabe H., Sasaki T., Maehama T., Frohman M. A., Kanaho Y., J. Biol. Chem., 277, 17226-17230 (2002) 